\section{JTI}

JOURNAL OF

TRAUMA AND INJURY

Received: August 25, 2019

Revised: November 1, 2019

Accepted: December 2, 2019

\section{Correspondence to}

McKenzie M. Hollon, M.D.

Department of Anesthesia, Emory University School of Medicine, 201 Dowman Dr

Atlanta, GA 30322, USA

Tel: +1-404-778-7777

Fax: +1-504-881-6238

E-mail:mmayo2@emory.edu

\title{
Resuscitation from a pH of 6.5: A Case Report and Review of Pathophysiology and Management of Extreme Acidosis from Hypovolemic Shock after Trauma
}

\author{
Alexander Balmaceda, M.D., Sona Arora, M.D., Ilan Sondheimer, M.D., \\ McKenzie M. Hollon, M.D. \\ Department of Anesthesia, Emory University School of Medicine, Atlanta, GA, USA
}

Extreme acidosis is a life-threatening physiological state that causes disturbances in the cardiovascular, pulmonary, immune, and hematological systems. Trauma patients commonly present to the operating room (OR) in hypovolemic shock, leading to tissue hypoperfusion and the development of acute metabolic acidosis with or without a respiratory component. It is often believed that trauma patients presenting to the OR in severe metabolic acidosis $(\mathrm{pH}<7.0)$ will have a nearly universal mortality rate despite aggressive resuscitation and damage control. The current literature does not include reports of successful resuscitations from a lower $\mathrm{pH}$, which may lead providers to assume that a good outcome is not possible. However, here we describe a case of successful resuscitation from an initial $\mathrm{pH}$ of 6.5 with survival to discharge home 95 days after admission with almost full recovery. We describe the effects of acute acidosis on the respiratory and cardiovascular systems and hemostasis. Finally, we discuss the pillars of management in patients with extreme acute acidosis due to hemorrhage: transfusion, treatment of hyperkalemia, and consideration of buffering acidosis with bicarbonate and hyperventilation.

Keywords: Acute metabolic acidosis; Shock, Hemorrhagic; Trauma 


\section{INTRODUCTION}

Hemorrhagic shock has been shown to be the leading cause of death in trauma patients presenting to the operating room (OR) [1]. In the setting of massive blood loss, under-resuscitation rapidly leads to a state of extreme acidosis with $\mathrm{pH}<7.0$. The development of extreme acidosis has profound effects on mortality, with only a third or fewer patients surviving to hospital discharge [2-4]. A retrospective study by Allyn et al. [4] found that the mortality rate differed based on the etiology of acidosis, with an $86 \%$ mortality rate for acidosis caused by hemorrhagic shock in their small series. However, we believe that extreme acidosis, even with a $\mathrm{pH}<6.8$, caused by hemorrhagic shock may be corrected and survivable with fast, effective resuscitation. Early acidosis has been described as a measurable base deficit in trauma patients in the first hour of admission, and it has been correlated with injury severity, significant hemorrhage, the development of coagulopathy, hypotension, and mortality. The dire prognosis of this severe condition is due to its impact on multiple organ systems. By demonstrating success in this case, we hope to encourage others to pursue aggressive care in patients with extreme acidosis from acute hypovolemic shock. Below, we report a case of successful resuscitation from a $\mathrm{pH}$ of 6.5 after penetrating trauma and review the pathophysiology and management of extreme acidosis. Written patient consent was obtained for publication.

\section{CASE REPORT}

A 22-year old male presented to the emergency department with gunshot wounds to his left abdomen, a heart rate (HR) of 125 beats/min, and non-invasive blood pressure (NIBP) of 60/palpable mmHg. Subclavian vein and tibial intraosseous lines were placed, the massive transfusion protocol was initiated, and he was transported to the OR for an emergent exploratory laparotomy after the infusion of 2 units of packed red blood cells (pRBCs) was started in the emergency department. Upon arrival to the OR, he immediately received 5 units of pRBCs, 2 units of fresh frozen plasma (FFP), and $260 \mu \mathrm{g}$ of epinephrine in divided doses, and he was intubated emergently. The ini- tial recorded vital signs were an NIBP of 102/51 mmHg, an HR of 66 beats/min, and no recorded oxygen saturation, with a fractional inspired oxygen concentration of 1.0. The patient was hemodynamically unstable, with wide variations in NIBP and HR. Initial blood gas results demonstrated a $\mathrm{pH}$ of 6.53 , a $\mathrm{pCO}_{2}$ of $76 \mathrm{mmHg}$, and a base excess (BE) of $-30 \mathrm{mEq} / \mathrm{L}$ (Table 1), consistent with a mixed acid-base disorder. The initial elevation of $\mathrm{pCO}_{2}$ was likely the result of hypoventilation in the emergency department and during subsequent transfer to the OR; however, it could also have been related to tissue washout of $\mathrm{CO}_{2}$ into the bloodstream after initial resuscitation efforts led to an increase in cardiac output. The resuscitation required a total of 49 units of pRBCs, 34 units of FFP, 3 units of platelets, and 6 units of cryoprecipitate. Additionally, other interventions included $2.26 \mathrm{mg}$ of epinephrine in divided doses, calcium chloride, tranexamic acid, sodium bicarbonate, and insulin. Surgical control of bleeding was attained through ligation of the branches of the left portal vein. Injuries included lacerations to segments 4 and 7 of the liver, a left portal venotomy, and a renal hematoma. The surgical time was 5 hours and the documented estimated blood loss exceeded 2 liters. The final arterial blood gas analysis in the OR demonstrated significant improvements in acidosis and base deficit, with a $\mathrm{pH}$ of $7.19, \mathrm{pCO}_{2}$ of $35 \mathrm{mmHg}, \mathrm{pO}_{2}$ of $227 \mathrm{mmHg}$, $\mathrm{BE}$ of $-14 \mathrm{mEq} / \mathrm{L}, \mathrm{HCO}_{3}$ of $13.5 \mathrm{mEq} / \mathrm{dL}$, and hematocrit of $37 \%$ prior to transfer to the intensive care unit.

The patient's hospital course included an enterocutaneous fistula development requiring multiple exploratory laparotomies and tracheostomy. Despite these abdominal surgical complications, he was discharged home 95 days

Table 1. Arterial blood gases

\begin{tabular}{|lcc|}
\hline & $\begin{array}{c}\text { Initial OR arterial } \\
\text { blood gas }\end{array}$ & $\begin{array}{c}\text { Final OR arterial } \\
\text { blood gad }\end{array}$ \\
\hline $\mathrm{pH}$ & 6.53 & 7.19 \\
$\mathrm{pCO}_{2}$ & 76.2 & 35 \\
$\mathrm{pO}_{2}$ & 134 & 227 \\
Base excess & -30 & -14 \\
$\mathrm{HCO}_{3}$ & 6.4 & 13.5 \\
$\mathrm{Hematocrit}$ & $13.3 \%$ & $37 \%$ \\
\hline
\end{tabular}

OR: operating room. 
after admission with an almost full recovery, requiring only wound care for his abdominal wound and mobility assistance for left foot drop.

\section{DISCUSSION}

Acidosis is defined as a $\mathrm{pH}<7.35$. In the trauma setting, acidosis is often a consequence of hypoperfusion due to hemorrhagic shock and is metabolic in nature. Without oxygen supply, peripheral tissues resort to anaerobic metabolism for energy production, thereby increasing the production of lactic acid. It has been proposed that $\mathrm{pH}$, serum lactate levels, and base deficit serve as biomarkers of shock in trauma patients, and these biomarkers correlate well as indicators of major injury and hypoperfusion in trauma [5].

While there is no consensus definition for what constitutes "severe" or "extreme" acidosis, many physicians may assume that patients presenting with a $\mathrm{pH}<7.0$ have a nearly universal mortality rate; however, there is literature to contradict this widespread belief. In a retrospective review published in 1998, as many as one-third of patients presenting with a $\mathrm{pH}<7.0$ survived to discharge, regardless of whether the etiology was metabolic, respiratory, or mixed. Nonetheless, when shock and coma were also present, there were no survivors among the 37 patients included [2]. In a more recent retrospective cohort study from $2017,11.1 \%$ of trauma patients presented in "profound" acidosis ( $\mathrm{pH}<7.0$ ), of whom $37.9 \%$ survived [3]. However, no patients with a $\mathrm{pH}$ of 6.6 or less have been reported to survive.

The disruption of acid-base homeostasis impacts the body's most vital functions (Table 1). The critical effects of acidosis on oxygenation and oxygen delivery include impacts on control of ventilation, perfusion of pulmonary capillaries, diffusion across the alveolar membrane, and binding and unbinding of hemoglobin [6].

The deleterious effects of metabolic acidosis on the cardiovascular system have been extensively studied. Numerous studies have shown that metabolic acidosis decreases cardiac contractility, even in cases of moderate metabolic acidosis ( $\mathrm{pH}<7.20$ ) [7]. It is thought that excess hydrogen ions decrease calcium release from the sarcoplasmic reticulum and reduce the sensitivity of cardiac myofilaments to calcium, thereby decreasing cardiac contractility. Furthermore, acidosis predisposes the myocardium to alterations in membrane polarization, increasing the risk of potentially fatal arrhythmias. Acidosis also causes increased pulmonary vascular resistance [8], translating to increased afterload on a right ventricle ill-equipped for higher downstream pressures.

Extreme acidosis has profound effects on the peripheral vasculature, leading to vasodilation refractory to many common vasopressors and inotropes, requiring much higher doses to achieve a clinical effect [7]. It has been hypothesized that these observed changes are the result of decreased relative binding affinities of inotropes and vasopressors to adrenergic receptors under acidotic conditions [9].

Another profound and harmful effect of acidosis in the hemorrhaging patient is its impact on hemostasis. A study in pediatric patients examined the relationship between early coagulopathy and metabolic acidosis on pRBC transfusion, and found that the initial base deficit was predictive of the amount of pRBC transfusion required [10]. Enzymatic reactions and proteins function most effectively within tight windows of temperature and $\mathrm{pH}$, with alterations causing conformational changes that denature proteins and lead to dysfunction.

Thromboelastography (TEG) has been used to study coagulation in healthy volunteers and has demonstrated increasing disturbances with acidosis. However, when compared with healthy patients, trauma patients experienced even greater derangements in TEG measures of coagulopathy [11]. This suggests that extreme acidosisalthough harmful in all patient populations-may be even more deleterious in trauma patients, in whom it exacerbates the triad of acidosis, hypothermia, and coagulopathy.

Management of extreme acidosis from massive hemorrhage requires the execution of multiple interventions aimed at reducing circulating acid levels and treating the side effects of decreased $\mathrm{pH}$ (Table 2). Success often hinges on the ability to eliminate acid from the body and to limit the production of more acid. The mechanisms of decreasing the circulating acid load include improving tissue perfusion, buffering, respiratory elimination, and re- 
Table 2. Pillars of management

\begin{tabular}{|c|c|c|c|}
\hline Transfusion & Consider hyperventilation & Consider bicarbonate & $\begin{array}{l}\text { Treat hyperkalemia and } \\
\text { prevent arrhythmia }\end{array}$ \\
\hline $\begin{array}{l}\text { Of pRBCs, FFP, PLTs in 1:1:1 ratio to } \\
\text { correct hypovolemia and prevent } \\
\text { development/worsening of coag- } \\
\text { ulopathy }\end{array}$ & $\begin{array}{l}\text { For respiratory compensation } \\
\text { metabolic acidosis }\end{array}$ & $\begin{array}{l}\text { Especially in the setting of an ad- } \\
\text { equate ability to hyperventilate, } \\
\text { with a low } \mathrm{pCO}_{2} \text { to } \mathrm{ETCO}_{2} \text { gradi- } \\
\text { ent, for improvement of coagu- } \\
\text { lopathy, vascular tone and cardiac } \\
\text { function }\end{array}$ & $\begin{array}{l}\text { Calcium administration, insulin, dex- } \\
\text { trose, beta agonism. Possible initi- } \\
\text { ation of renal replacement therapy } \\
\text { post-operatively }\end{array}$ \\
\hline
\end{tabular}

PRBCs: packed red blood cells, FFP: fresh frozen plasma, PLTs: platelets.

nal elimination. Given that metabolic acidosis in trauma patients presenting in hemorrhagic shock is most often the result of decreased tissue perfusion, the most obvious approach to correction of acidosis is intravascular resuscitation along with control of hemorrhage. Transfusion is the preferred means of resuscitation in hemorrhagic trauma patients. The overall goals are to treat any intravascular deficits, to prevent or reverse coagulopathy, and to improve oxygen delivery.

Buffering blood $\mathrm{pH}$ is a strategy employed to decrease circulating acid load. The use of sodium bicarbonate has been avoided by some due to concerns about whether cardiac performance may be worsened by the resultant decrease in ionized calcium levels and induction of intracellular acidosis. Wilson et al. [12] demonstrated increased mortality in trauma patients with a $\mathrm{pH}<7.10$ who received more than 5 ampules of sodium bicarbonate. Interestingly, the patients who did not survive had a widened $\mathrm{pCO}_{2}$ to $\mathrm{ETCO}_{2}$ gradient. This suggests that an inability to decrease $\mathrm{pCO}_{2}$ via hyperventilation in the setting of bicarbonate administration and the subsequent exacerbation of respiratory acidosis may play a role in decreased survival. However, a study in a rat model demonstrated that the concomitant use of bicarbonate therapy with calcium administration and mechanical hyperventilation normalized arterial $\mathrm{pH}$, cardiovascular function, and vascular responsiveness to exogenous norepinephrine [13]. This suggests the need for appropriate ventilation, lung function, and the ability to adequately hyperventilate when introducing bicarbonate in this setting.

The use of goal-directed hyperventilation is another reasonable strategy to compensate for metabolic acidosis. In the case presented above, with a picture of "mixed" acidosis, hyperventilation would be warranted to correct for the respiratory component. However, after correction of respiratory acidosis, it remains unclear if continued hyperventilation is of benefit. Currently, no studies have directly investigated hyperventilation in the trauma setting, although the administration of sodium bicarbonate with hyperventilation appears to offer benefits for the correction of severe metabolic acidosis until adequate volume resuscitation and hemorrhage control can be achieved. However, animal models of cardiopulmonary resuscitation have shown that survival rates were worse in animals ventilated at rates of 30 breaths/min [14] due to significantly increased intrathoracic pressure and markedly decreased coronary perfusion pressures. Therefore, more research is needed to define the role of hyperventilation in trauma patients, and until then the strategy may depend on whether the patient's venous return is clinically impacted by the increased intrathoracic pressure of hyperventilation. Treatment of additional electrolyte abnormalities, such as hyperkalemia, that are the result of poor tissue perfusion and acidosis must also be addressed. Initiation of exogenous blood hemofiltration in the form of continuous renal replacement therapy or hemodialysis may also play a role in the future in the resuscitation of trauma patients, although barriers to its use currently include difficulties in implementation, hemodynamic concerns, and lack of evidence for its use [15].

The management of extreme acidosis from hemorrhagic shock is multifaceted, and is often partially based on clinical judgment rather than established evidence (Table 2). Rapid resuscitation of intravascular volume, maintenance of peripheral perfusion, and correction of coagulopathy are pillars of management. Administration 
of buffer, hyperventilation, and renal replacement therapy may also play a supporting role in the resuscitation of extreme acidosis in trauma and their use should be considered on an individual basis. With a rapid response and a multi-pronged approach in the right patient, it is possible to successfully resuscitate patients from even very extreme acidosis.

\section{REFERENCES}

1. Kauvar DS, Lefering R, Wade CE. Impact of hemorrhage on trauma outcome: an overview of epidemiology, clinical presentations, and therapeutic considerations. J Trauma 2006;60(Suppl):S3-11.

2. Robertson R, Eidt J, Bitzer L, Wallace B, Collins T, Parks-Miller $\mathrm{C}$, et al. Severe acidosis alone does not predict mortality in the trauma patient. Am J Surg 1995;170:691-4.

3. Ross SW, Thomas BW, Christmas AB, Cunningham KW, Sing RF. Returning from the acidotic abyss: mortality in trauma patients with a $\mathrm{pH}<7.0$. Am J Surg 2017;214:1067-72.

4. Allyn J, Vandroux D, Jabot J, Brulliard C, Galliot R, Tabatchnik X, et al. Prognosis of patients presenting extreme acidosis $(\mathrm{pH}<7)$ on admission to intensive care unit. J Crit Care 2016;31:243-8.

5. Caputo N, Summersgill A, Fraser R, Kanter M. 175 determining the utility of metabolic acidosis in trauma patients. Ann Emerg Med 2013;62:S66.

6. Mitchell JH, Wildenthal K, Johnson RL Jr. The effects of acidbase disturbances on cardiovascular and pulmonary function. Kidney Int 1972;1:375-89.

7. Schotola H, Toischer K, Popov AF, Renner A, Schmitto JD,
Gummert J, et al. Mild metabolic acidosis impairs the $\beta$-adrenergic response in isolated human failing myocardium. Crit Care 2012;16:R153.

8. Kim SI, Shoemaker WC. Role of the acidosis in the development of increased pulmonary vascular resistance and shock lung in experimental hemorrhagic shock. Surgery 1973;73:723-9.

9. Modest VE, Butterworth JF 4th. Effect of $\mathrm{pH}$ and lidocaine on beta-adrenergic receptor binding. Interaction during resuscitation? Chest 1995;108:1373-9.

10. Smith SA, Livingston MH, Merritt NH. Early coagulopathy and metabolic acidosis predict transfusion of packed red blood cells in pediatric trauma patients. J Pediatr Surg 2016;51:848-52.

11. Lv X, Mao Y, Qin Z. Evaluation for effects of severe acidosis on hemostasis in trauma patients using thrombelastography analyzer. Am J Emerg Med 2018;36:1332-40.

12. Wilson RF, Spencer AR, Tyburski JG, Dolman H, Zimmerman LH. Bicarbonate therapy in severely acidotic trauma patients increases mortality. J Trauma Acute Care Surg 2013;74:45-50.

13. Kimmoun A, Ducrocq N, Sennoun N, Issa K, Strub C, Escanyé $\mathrm{JM}$, et al. Efficient extra- and intracellular alkalinization improves cardiovascular functions in severe lactic acidosis induced by hemorrhagic shock. Anesthesiology 2014;120:926-34.

14. Aufderheide TP, Sigurdsson G, Pirrallo RG, Yannopoulos D, McKnite S, von Briesen C, et al. Hyperventilation-induced hypotension during cardiopulmonary resuscitation. Circulation 2004;109:1960-5.

15. Haines RW, Fowler AJ, Kirwan CJ, Prowle JR. The incidence and associations of acute kidney injury in trauma patients admitted to critical care: a systematic review and meta-analysis. J Trauma Acute Care Surg 2019;86:141-7. 